\title{
Chapter 21 \\ Reordering Occupation, Race, and Place in Metropolitan New York
}

\author{
Kasey Zapatka, John Mollenkopf, and Steven Romalewski
}

\begin{abstract}
The New York metropolitan area is one of the oldest, largest, and perhaps most complex urban region in the United States (U.S.). Its 23.7 million residents live across four states, produce a GDP of more than $\$ 1.7$ trillion, are governed by a fragmented political system, and experience persistently high degrees of geographic and racial/ethnic inequality and segregation. This chapter investigates the evolving spatial organization of occupation and race across the metropolitan area. While white professionals have traditionally lived in an outer ring of suburbs and blue-collar immigrant and minority groups have lived closer to the city center, our research shows that the forces of gentrification and minority and immigrant suburbanization have been turning the metropolitan area inside out. Specifically, young, usually white, professionals are increasingly located in and around the central city whereas many working-class minorities have shifted away from it. At the heart of this spatial reordering lie the diminishing plurality of native-born whites within the region and the increasing share of immigrant minority groups, especially for foreign-born Hispanics and Asians. This trend has lessened the share of white males in better occupations even as the region's occupational structure slowly but inexorably tilts toward managerial and professional occupations. Technology is transforming white-collar work as blue-collar work continues to disappear. Dramatic shifts are thus afoot, yet inequality
\end{abstract}

Electronic supplementary material The online version of this chapter (https://doi.org/10.1007/978-3-030-64569-4_21) contains supplementary material, which is available to authorized users.

\section{K. Zapatka $(\bowtie)$}

Department of Sociology, City University of New York, The Graduate Center, New York, NY 10016, USA

e-mail: kzapatka@gradcenter.cuny.edu

\section{J. Mollenkopf}

Department of Political Science and Sociology, City University of New York, The Graduate Center, New York, NY 10016, USA

e-mail: JMollenkopf@gc.cuny.edu

S. Romalewski

CUNY Mapping Service, City University of New York, The Graduate Center, New York, NY 10016, USA

e-mail: SRomalewski@gc.cuny.edu 
and segregation remain high. We argue that these changes in the spatial organization of the metropolitan area challenge us to see these inequalities from a new vantage point. As elites are now more likely to live among less advantaged groups, this may provide the social basis for new thinking.

Keywords New York metropolitan area $\cdot$ Demographic change $\cdot$ Spatial inequality $\cdot$ Immigrant suburbanization $\cdot$ Segregation

\subsection{Introduction}

The New York metropolitan region is old, large, and complex. Settlers sent by the Dutch West India Company founded the colony on Lenape Native American land in 1624 at the southernmost tip of present-day Manhattan. The great protected harbor at the confluence of the Hudson River and the East River provided water access not only along the East Coast of the U.S., but also north and west to the Great Lakes and the inland U.S. (especially after the Erie Canal was completed in 1825). New York City firms made the most of these advantages, achieving dominance over the U.S. and the trans-Atlantic trading systems in the mid-nineteenth century. Building on these initial advantages, a vast regional system of work, residence, and recreation grew up around the city over time.

Today, the broadest official definition of the metropolitan region is the U.S. Census-defined Combined Statistical Area (CSA). The border of the New York CSA stretches from Atlantic City on the southern New Jersey coast northwest to Allentown, Pennsylvania, eastward across the Hudson River valley to Connecticut, and then southeast across the Long Island Sound to include the length of Long Island. This broad definition encompasses 23.7 million residents and more than 10 million workers producing a $\$ 1.7$ trillion GDP - ten percent of the U.S. total. More than a third of these residents live in or just outside New York City at high-density levels (656 people per square kilometer or more). Narrower definitions of the metropolitan area include the U.S. Census-defined Core-Based Statistical Area (CBSA) and the OECD Functional Urban Area (FUA). The CBSA contains almost 20 million people and 9.8 million workers but excludes Connecticut and distant subordinate metro areas. This chapter analyzes patterns in the even smaller FUA delineation, pictured in Fig. 21.1. It consists of 16 New York and New Jersey counties accounting for 17 million people and 8.3 million workers. The denser, inner FUA thus contains almost three-quarters of the broader CSA population and four-fifths of its labor force.

The FUA's metropolitan hierarchy centers on one large, dense city (New York) surrounded by other smaller but still substantial cities (New Brunswick, Newark, Jersey City, Yonkers, White Plains, and the major Long Island towns) and an extensive network of suburbs. At present, New York City contains half of the FUA population8.6 million residents, 4.1 million workers, and 4.6 million jobs, four-fifths of which are held by city residents. The FUA's satellite cities and suburbs contain the other half of the FUA's residents, with 8.4 million dwellers, 4.2 million workers, and 3.6 million 


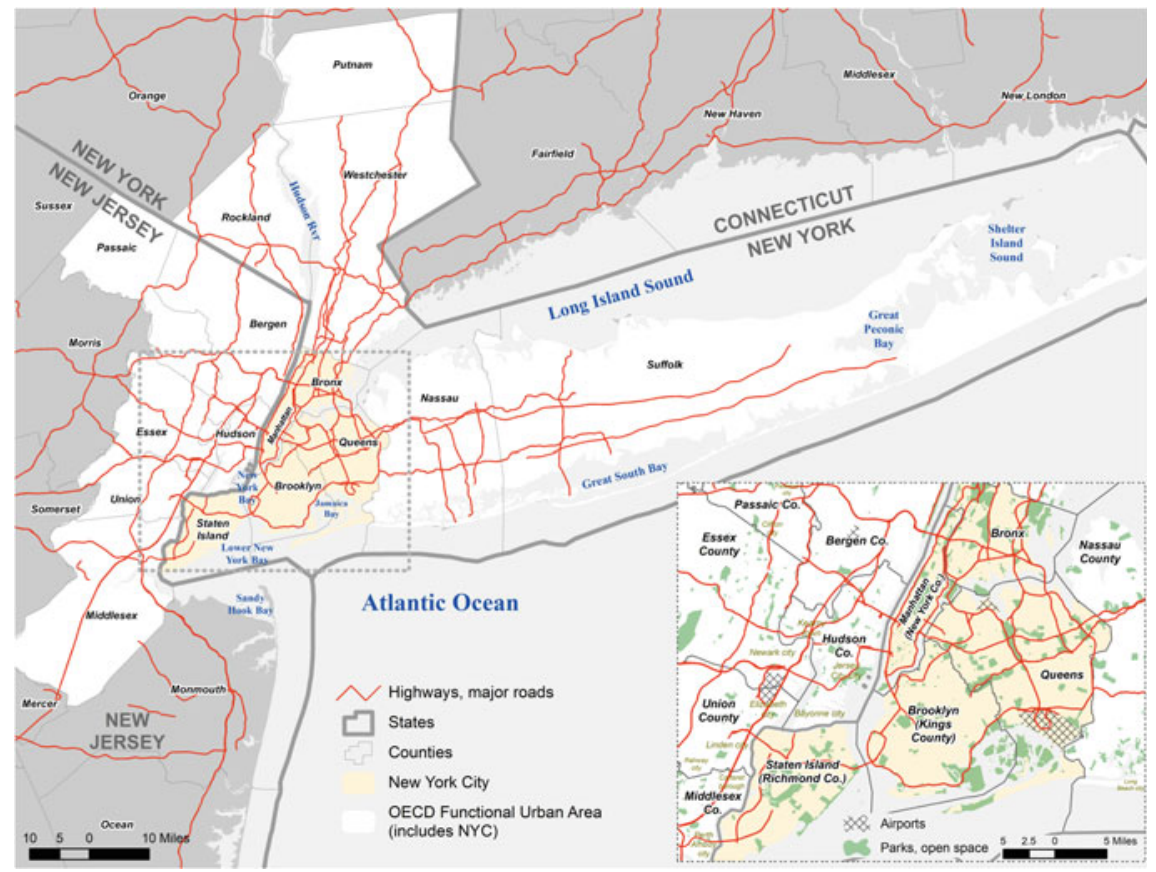

Fig. 21.1 Geography of New York metropolitan area (OECD Functional Urban Area)

jobs, which are overwhelmingly held by people living outside the city. About 790,000 suburban workers commute into the central city, while approximately 300,000 city residents work outside its boundaries. ${ }^{1}$

A multi-nodal, radial system of mass transit, highways, bridges, tunnels, and roads knits together the regional patterns of residence and work. While the core city is governed by a cohesive and centralized municipal government, the rest of the region is fragmented into several states and more than a thousand municipal jurisdictions, all of which have developed distinct social fabrics and identities. Patterns of defensive incorporation hardened these jurisdictional boundaries by the end of the nineteenth century, with some suburban towns using zoning and housing regulations to attract and serve better-off residents and leaving other places to house and serve the working classes.

These arrangements produced and reinforced a persistently high, if gradually declining, level of racial segregation, indeed currently the second highest of any

\footnotetext{
${ }^{1}$ As described below, sources include the 2000 U.S. Census STF3 tract file and Public Use Microdata Sample (PUMS) File and the American Community Survey (ACS) combined tract and public use microdata files for 2008-2012 and 2013-2017. Since the ACS is a rolling five-year average, we refer to 2008-2012 and 2013-2017 by their end year, 2012 and 2017, respectively, for simplicity. Employment by place figures come from the U.S. Bureau of Labor Statistics. The numbers here were calculated from the PUMs File using the person weight and excluding all people not living in households (i.e., group quarters).
} 
U.S. metro area (Frey 2018). As it does elsewhere in the United States, class has a color in New York, since racial and ethnic groups cluster in specific occupations and industries. Whites are strongly represented in top occupations in the higher value-added industries while minority groups cluster in less rewarding occupations and industries (Waldinger 1996). ${ }^{2}$ The residential segregation of different racial and ethnic groups is thus intimately intertwined with patterns of socioeconomic segregation and inequality. As the remainder of this analysis specifically discusses the regional occupational and socioeconomic patterns of FUA, readers should keep the patterns of the larger metropolitan region in mind.

\subsection{Background: Changing Occupational Structures and Patterns of Inequality and Segregation}

New York exemplifies the post-World War II American metropolis. From the 1950s through the 1980s, the decline of population and employment in inner cities with growing minority populations was a key feature of this regional mosaic. By contrast, growing suburbs attracted the white middle-class residents and workers with new housing, shopping malls, and corporate office parks. Since then, however, three potent forces have gradually begun to erode and alter this pattern. The first is demographic (declining native and rising immigrant-origin populations), the second involves occupational restructuring (the shift from production to services with a new ethno-racial and gender division of labor), and the third concerns the shifting geography of population concentrations (a shift in residential locations).

\subsubsection{The Decline of the Native-Born and the Rise of Immigrant-Origin Populations}

The twin patterns of declining native-born and rising immigrant-origin populations are reshaping the metropolitan region. The number and share of people living in households headed by native-born non-Hispanic whites have declined relatively and absolutely not just in the older central cities like New York City or Newark, but also in the whole region, falling from 6.4 to 5.9 million between 2000 and 2017 and from 52.1 to $47.9 \%$ of the FUA total. This story of the native white population decline

\footnotetext{
${ }^{2}$ The U.S. Census collects information separately on race and Hispanic origin. In analyzing census data, social scientists almost always group all Hispanics together as a distinct group, leaving nonHispanic whites, blacks, Asians, and other races as the other categories. When we use the terms white, black, and Asian, we mean the non-Hispanic portions of those populations. Since "Hispanic" is the official Census term, we use it here, although sometimes preferred alternatives are "Latino/a" or "Latinx". The census PUMS also ask respondents about their ethnic ancestries, places of birth, and citizenship status, allowing researchers to identify specific ethnic groups (e.g., Irish, Italian, Jamaican, or Dominican).
} 
is relatively old, but the pattern now also extends to native African American and Puerto Rican households (For most of the period between 1950 and 1980, Puerto Ricans contributed to the vast majority of Hispanic households). Membership in African American households declined by 129,000 and Puerto Rican households by 59,000 . If this had been the only trend, the region would have shrunk greatly, just as it did on other rustbelt areas, but native out-migration was not the only force at work. The number of people living in immigrant-origin households grew within all the racial categories, more than offsetting the native declines. ${ }^{3}$ The immigrant-headed household population surged by 1.34 million to $43.5 \%$ of the FUA total. As a result, the FUA's total population rose $6.5 \%$ between 2000 and 2017.

Ever since African Americans and Puerto Ricans became substantial groups in the region, high levels of white-black segregation and lower but still high levels of whiteHispanic segregation have characterized metropolitan residential patterns. Occupational segregation was lower, yet still considerable. Over time, however, deindustrialization and the shift to services have altered the types of industries and occupations in the regional economy. As new immigrant-origin racial and ethnic groups entered the metropolitan labor market, they tended to cluster in specific industry-occupation niches that were open to them because native groups were departing them, these occupations were less desirable to native workers, job growth outstripped the supply of native-born workers, or immigrant entrepreneurs found ways to enter them. Entering groups competed with each other to access the available niches that offered higher wages and more opportunity and achieve ethnic closure within them (Waldinger 1996). While workers from every ethnic or racial group span every occupation and industry, they do so unevenly, achieving significant clustering in some niches and remaining relatively sparse in others. To give one example, native-born whites make up $41.6 \%$ of the workers in the FUA, yet they hold $65 \%$ of the chief executive and only $6.9 \%$ of the dishwasher positions. Conversely, foreign-born Hispanics (12.6\% of all workers) hold only $2.7 \%$ of chief executive positions but are $61.4 \%$ of the dishwashers. Racial and occupational segregation thus intertwine to create distinctive patterns in the geography of the labor force.

\subsubsection{New Ethno-Racial and Gender Divisions of Labor}

The interaction between economic and demographic change between 2000 and 2017 has gradually reshaped the ethno-racial and gender division of labor in the region. The dominance of suburban white males in the top occupations has diminished and inner-city minorities have slowly shifted away from low-paid service jobs. Women, minorities, and immigrants now hold increasing shares of higher-paying jobs. ${ }^{4}$ Of

\footnotetext{
${ }^{3}$ We group people by the characteristics of the household head because this identifies the immigrant origin of native-born children with foreign born parents.

${ }^{4}$ Gender and family patterns are a critical part of this story, as more women enter the labor force and more families rely on two earners. Ideally, our analyses would not only take race and nativity into
} 
course, dominant groups may still try to ensure that members of their own or other favored groups will succeed them by maintaining barriers to immigrant and minority upward occupational mobility. However, the declining number and share of workers from native-born groups, especially whites, and the rising shares of workers from minority immigrant households make it impossible for them to do so fully. White males are aging out of the Top occupations and younger cohorts do not contain enough white males to replace them. This has opened paths for what Richard Alba (2009, p. 15) has called "non-zero sum upward mobility."

\subsubsection{A Shift in Residential Locations}

Another important force reshaping the metropolitan area has been the shift in the residential preferences of younger native-born, non-Hispanic white managers and professionals away from their former distant suburban strongholds toward racially diverse neighborhoods in and around the central city (see Ley 1996; Smith 1996 for competing theories as to why and how this occurs). This has been paired with the outward movement of minority and immigrant workers. The period from 2000 to 2017 has been one of changing places: native white professionals and managers shifting into increasingly white, inner-city neighborhoods and minority and immigrant workers in the middle and lower occupations shifting into decreasingly white, inner suburban areas.

"Given the strong correlation between income and race in the United States" (Reardon and Bischoff 2011, p. 1093), it is hardly surprising that racial succession has resulted in declining real median household incomes in many inner suburbs. For example, between 2000 and 2017, the blue-collar city of Bayonne, New Jersey, suffered a net loss of 20,000 people living in white native-born households and 5,000 living in black native-born households, yet it gained 6,000 people living in black immigrant households, 11,000 in native Hispanic households, 15,000 in immigrant Hispanic households, 1,800 in native Asian households, and 11,000 in immigrant Asian households, thus more than offsetting native-born losses. At the same time, Bayonne's real median household income per capita declined by $5.5 \%$. Reciprocally, the increasing movement of white, middle-class residents into many low-income inner-city neighborhoods has raised their median incomes. The gentrifying Brooklyn neighborhoods of Greenpoint, Williamsburg, East Williamsburg, and Bushwick collectively attracted 85,700 more people living in native white households while losing 19,300 members of native black households and 12,200 members of native Hispanic households. Real median household income per capita rose to $68 \%$, erasing many of the previous effects of deindustrialization, disinvestment, and depopulation on these neighborhoods.

account, but gender as well in terms of how groups are sorted across industry-occupation niches. We refrain from exploring that here because adding gender to the analysis would increase the eight major racial-nativity categories to sixteen. 
More broadly, people with good jobs and high incomes have been recentralizing in recent years after diffusing away from their central cities in previous decades (Shearer et al. 2019). Although white managers and professionals and their families still live mainly in affluent suburbs located 30 to 40 miles away from Manhattan, the center of gravity of the net shift in this population has moved strongly toward neighborhoods surrounding the Manhattan central business district, including Harlem, the East River communities in Queens and Brooklyn, and Hoboken and Jersey City across the Hudson River. Simultaneously, the poor, minorities, and immigrants previously concentrated in central cities are shifting toward the inner suburbs beyond this gentrifying ring. While the overall spatial patterns of economic and social difference still bear many marks of the post-World War II period, they are clearly changing. If suburbanization of the white middle class and the growth of the central city minority poor defined the metropolitan form between 1950 and 1980, the recentralization of young professional households (primarily but not exclusively white) and the gradual dispersal of native and immigrant minority group members mark the period between 1980 and the present. A complicated mix of factors is shaping this dynamic, including changing preferences among those who have a choice of where to live, rising central city housing costs that directly or indirectly displace some former residents, and the fading of a post-World War II generation of suburban housing and family formation choices.

Economic restructuring has changed the mix of occupations; demographic change has altered the make-up of their workers; and altered location patterns have shifted the mosaic of jobs, residences, and commutes in the metropolitan area. This is particularly evident between the Manhattan central business district and the distant affluent, white suburbs. The predominantly black and Hispanic inner-city communities that experienced the largest gains in white residents were all in Brooklyn areas with good transit connections to Manhattan (Bed-Stuy, Crown Heights, Fort Greene, East Williamsburg, and Bushwick), or in Northern Manhattan (Harlem, West Harlem, East Harlem, and Washington Heights). Collectively, these communities gained 248,000 employed workers, doubled their number of managers and professionals, and lost office and factory workers. The overall drop in the FUA's white population reduced their standing in many communities, especially the inner suburbs on Long Island and in New Jersey. Arriving minorities (especially immigrant Asian and Hispanic households) more than offset the white population's departure. While these communities slowly gained employed workers, managers, and professionals, these communities' biggest gains were in health support occupations, food preparation, home, child and healthcare aides, and other service jobs.

While New York remains one of the country's most racially segregated metro areas (Logan and Stults 2011, p. 6), its core white and black neighborhoods are not as white or black today as they were in 2000. Hispanic and Asian immigrant households have settled in and between them, blurring their boundaries; new kinds of "global neighborhoods" have emerged in the process (Zhang and Logan 2016). The subsequent analysis investigates how the spatial redistribution and repositioning of racial and occupational groups have created new occupational mixtures and juxtapositions. 


\subsubsection{The Influence of the Welfare System}

The U.S. has a comparatively fragmented welfare state that relies heavily on private provision (e.g., employer-sponsored healthcare and retirement systems) (Lynch 2014). The welfare system is largely funded by the federal government, but some states minimize or maximize the variety and quantity of services provided. In that context, New York and New Jersey have relatively extensive welfare systems, with New York City being one of the most social-democratic jurisdictions in the U.S. Its current Fiscal Year 2020 budget is $\$ 92.8$ billion, spending large amounts on housing, social services, and other redistributive programs. The Department of Homeless Services alone will spend $\$ 2.1$ billion. The City finances this high level of spending with the highest level of municipal taxation in the U.S. (Independent Budget Office 2007). While government spending levels are somewhat lower elsewhere in the region, the entire FUA is a relatively high tax, high public spending environment. Public employment is thus an important part of the labor market, with government contracts also sustaining high levels of employment in nonprofit organizations. New York City may be the business capital of the United States, but it also has the largest municipal hospital system; a huge municipal elementary, high school and university educational system; and a vast array of nonprofit organizations. Together, these systems help to sustain a substantial set of middle-income occupations held by City residents.

\subsubsection{The Influence of Housing and Land Tenure}

Before World War II, the vast majority of American households rented their homes; after the war, U.S. housing policy dramatically shifted in favor of homeownership (Schwartz 2015). As the Federal Housing Administration (FHA) instituted 30-year self-amortizing mortgages, insured mortgages issued by qualified lenders, instituted construction standards, and required housing inspections before sale, the Federal Housing National Mortgage Association (Fannie Mae) also purchased and securitized FHA-issued mortgages to provide capital so banks could issue more loans. Additionally, homeowners began deducting mortgage interest from their federal taxes, significantly subsidizing homeownership and making it more affordable than renting. As a result, the national homeownership rate grew from $44 \%$ in the 1940 s to $62 \%$ in the 1960s. (Schwartz 2015). As of April 2019, it hovers at 64.2\% (U.S. Census Bureau 2019).

Although these policies benefited many homeowners, systematic racial discrimination in lending and home sales prevented many minority groups from sharing in the gains. Restrictive covenants-private agreements preventing owners from selling to non-whites-were legal until 1948. FHA guidelines initially enshrined banking practices of refusing to lend in certain neighborhoods and did little to alter these practices even after Congress passed the Fair Housing Act in 1968 (Schwartz 2015). Failure 
to aggressively enforce the Fair Housing Act has left informal but systematic racial discrimination in place, maintaining segregation and limiting minority groups' ability to leverage homeownership to generate wealth and transfer it between generations.

While homeownership predominates in the suburban areas of metropolitan New York, approximately $65 \%$ of City residents rent their homes, since high housing costs limit access to homeownership. Compared to other cities, New York City has strong rent regulation laws and a substantial stock of public housing. While $43 \%$ of New York City renters live in market-rate housing, $45 \%$ are protected by rent regulation and another $12 \%$ live in other types of regulated units, which is largely public housing (New York City Rent Guidelines Board 2018, p. 4). ${ }^{5}$ Recently strengthened, these laws provide a degree of affordability and stability to renters in New York City (Paybarah 2019). As a result, median gross rent for all New York City renters was reported to be $\$ 1,830$ in 2017, but $\$ 1,375$ for rent-stabilized units (Gaumer 2018). It is against this backdrop that our analysis examines shifting patterns of residential segregation, growing income inequality, and a changing occupational structure over time.

\subsection{Data and Methods}

We created two datasets for our analysis: one spatial and the other individual. The first uses tract-level data from three time periods: the 2000 Decennial Census and the 2008-2012 and 2013-2017 American Community Survey (ACS) 5-year Estimates. ${ }^{6}$ The second dataset is an individual-level dataset drawn from University of Minnesota's Integrated Public Use Microdata Series (IPUMS). ${ }^{7}$ These data include two time periods that mirror the start and end of the spatial dataset; we used the $5 \%$ public use microdata sample from the 2000 Census as well as the public use microdata sample from the 2013-2017 ACS 5-year estimates (hereafter referred to as 2017). The census tract dataset provides a spatial analysis of small neighborhood areas called census tracts, which are small geographic areas that contain on average about 4,000 people. The second dataset provides a repeated cross-sectional analysis of individual and household data for geographic areas called Public Use Microdata Areas (PUMAs) that hold at least 100,000 people. The first dataset allows us to

\footnotetext{
5 "Other types of regulated units" largely consists of public housing, but also incldues Mitchell-Lama, In Rem, HUD-regulated, Article 4, and Loft Board units.

${ }^{6}$ U.S. Census data can be found at https://www.census.gov/programs-surveys/acs. We used the 2008-2012 ACS 5-Year Estimates instead of the 2010 Decennial Census since the ACS 5-Year Estimates are meant to give a better sense of what is happening over five-year periods than the snapshot the Decennial Census offers. Additionally, the ACS 5-Year Estimates provides much greater demographic and economic detail than does the Decennial Census, which counts population only by age, sex, race, and housing tenure. Since the ACS is a rolling five-year average, we refer to 2008-2012 and 2013-2017 by their end year, 2012 and 2017, respectively.

${ }^{7}$ IPUMS has received several federal grants to harmonize and integrate U.S. Census microdata, which can be accessed on their website: https://usa.ipums.org/usa/.
} 
analyze occupational trends by a neighborhood of residence within the FUA while the second allows us to analyze any combination of factors (including race, age, sex, education, and detailed occupation) for individuals and households within the larger PUMA areas. ${ }^{8}$ (The FUA contains 4,652 census tracts nested within 151 PUMAs.) We use the terms census tract and neighborhood interchangeably and refer to PUMAs as communities.

Since census tract boundaries change over time, we used the Longitudinal Tract Database (Logan et al. 2014) to harmonize data from 2000 into 2010 boundaries, the same boundaries used in the subsequent ACS data panels. All monetary values in both databases were inflation adjusted to 2018 dollars using the Consumer Price Index (CPI) for New York-Newark-Jersey City, NY-NJ-PA (U.S. Bureau of Labor Statistics 2019a). We inflation-adjusted housing-related variables using the all-itemsless-shelter CPI so as to not control away variation in housing costs across years (U.S. Bureau of Labor Statistics 2019b). ${ }^{9}$

\subsubsection{Measures of Inequality}

The most widely used measure of income inequality is the Gini coefficient (Hoque and Clarke 2015; Peñaloza 2016). Although these coefficients are typically calculated for individual or household incomes, we use them to examine the spatial patterns of inequality over time in the metropolitan area. The U.S. Census Bureau calculated tract-level Gini coefficients of income inequality for the two panels of tract data in our analysis but not for the 2000 Decennial Census. To create consistent measures across our data, we therefore used the von Hippel and colleagues' (2017) method of the cumulative distribution function and mean matching to approximate Gini coefficients with ordinal categorical data on household income from each of the three Census periods (see Peñaloza 2016; Reardon and Bischoff 2011; von Hippel et al. 2016, 2017). When we compare our results with the Census estimates from the two ACS tract data panels, they slightly underestimate the Gini's reported by the Census Bureau. This gives a slight conservative bias to our analysis of the changing spatial patterns of inequality compared to what we would find if we had Census Bureau-calculated Gini coefficients for all three periods.

\footnotetext{
${ }^{8}$ While both datasets are repeated cross-sectional, we refer to the first dataset that uses census tracts as the spatial dataset and the second that uses individual data as the cross-sectional dataset.

${ }^{9}$ The all-items-less-shelter CPI is similar to the all-items CPI; however, it does not include housing in its calculations of the overall CPI.
} 


\subsubsection{Measures of Residential and Socioeconomic Segregation}

We used the U.S. Department of Labor's Bureau of Labor Statistics O*NET Resource Center to condense census occupational categories into their appropriate ISCO categories (O*NET 2019 and Bureau of Labor Statistics 2019c). Similarly, we calculated location quotients and dissimilarity indices according to the methodology described in Chap. 1. However, we slightly departed from these methods in two ways. Since the socioeconomic distribution in the New York City metropolitan area skews toward the high end, we altered the socioeconomic classification of neighborhoods used in Fig. 21.4 to be exhaustive of all neighborhoods (Appendix reports our alternative classification scheme.) Second, we used the SEG package in Stata developed by Reardon and Townsend (1999) to calculate dissimilarity indices.

\subsection{Spatial Analysis}

\subsubsection{Changes in Income Inequality}

According to the World Bank, between 1979 and 2016 the Gini coefficient for income inequality in the U.S. increased by one-fifth, from 34.6 to 41.5 (World Bank 2019). The largest increases happened between 1979 and 1986, rising from 34.6 to 37.5 , rising again to 38.8 between 1991 and 1994 and then increasing more slowly, by $2.7 \%$ points, from 2000 to 2016 . In short, income inequality grew dramatically across the United States in the early 1980s and early 1990s, but then grew more slowly between 2000 and the present, in part because of major recessions.

Metropolitan New York has a slightly different story. We calculated Gini coefficients separately for each neighborhood and the entire FUA. The average Gini across all FUA neighborhoods started at 42.6 in 2000, dropped slightly to 41.6 in 2012 (as the regional economy experienced recession), and then rebounded to 42.6 in 2017 (as the region recovered). The index fell primarily because the financial crisis reduced the highest incomes. While this level of inequality is high by international standards, this average neighborhood inequality rests just above U.S. levels as reported by the World Bank. In contrast, the Gini index for the overall FUA is higher, beginning at 47.8 in 2000 , rising to 48.0 in 2012 , and rising again to 48.8 in the 2017 period. The inequality of the overall metropolitan area is thus higher than that of the average neighborhood—as much as 6.2 points higher in 2017.

\subsubsection{Changes in Occupational Structure}

Figure 21.2 reports how the Top, Middle, and Bottom occupational shares have 

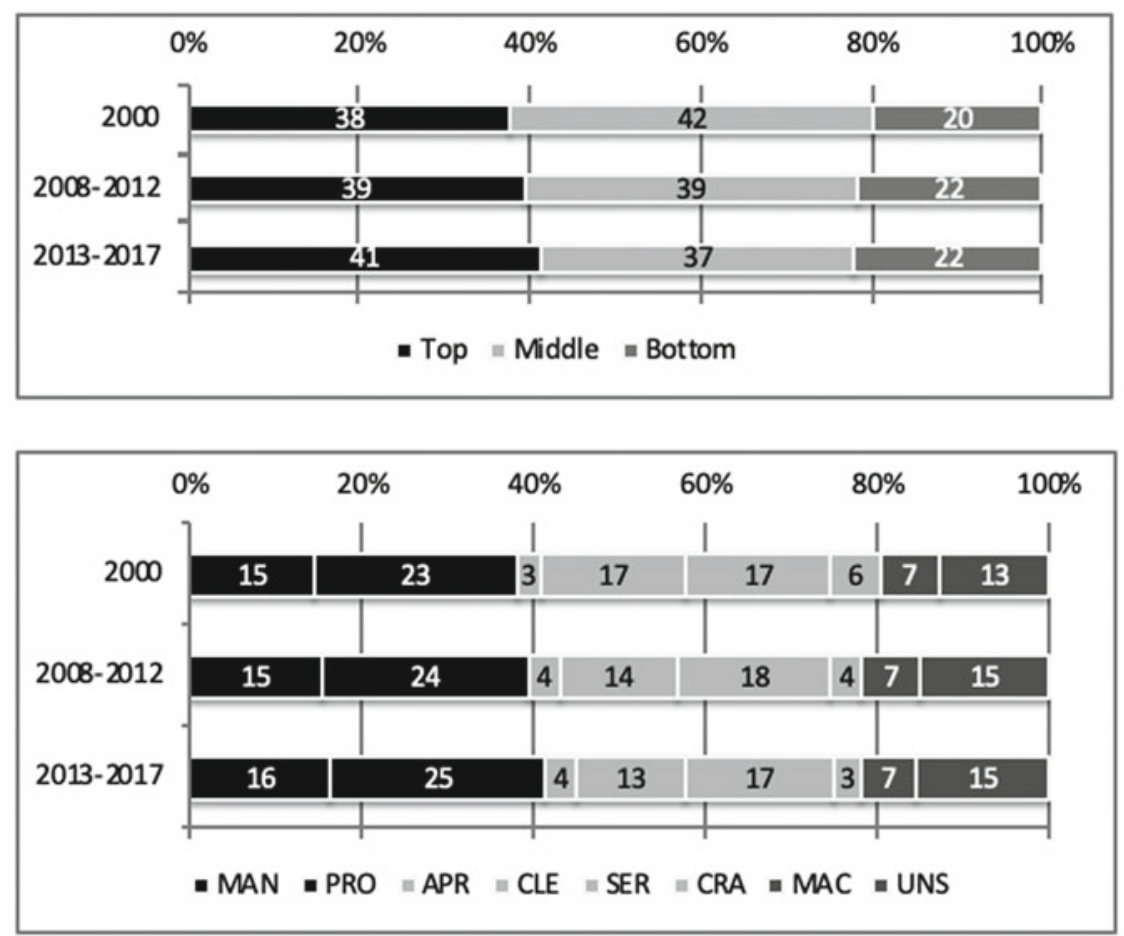

Ien: MAN = Managers, PRO = Professionals

Middle: $\mathbf{A P R}=$ Associate professionals, $\mathbf{C L E}=$ Clerks, $\mathbf{S E R}=$ Service workers, $\mathbf{C R A}=$ Craft workers Bottom: MAC $=$ Machine workers, UNS = Unskilled workers

Fig. 21.2 Distribution of occupational groups and change over time

evolved slowly over the study period, gradually becoming more polarized. The share of Top occupations increased three percentage points from 2000 to 2017, the Bottom increased two percentage points, and the Middle decreased five percentage points. The increases in Top occupational groups were evenly distributed among managers and professionals, while the increases in the share of Bottom occupational groups were concentrated in unskilled workers. This reflects not only New York City's role as a national node in commercial and investment banking and the advanced corporate services as well as higher education and hospitals, but also the important role of lowskilled personal services of various types. The losses for the Middle occupational groups were concentrated in the shares of clerks and craft workers. Our research shows that in 2000 , these occupations were concentrated around central cities like 
New Brunswick and Newark in New Jersey, as well as in the Bronx, Queens, and along the central strip of Long Island. However, by 2017, these concentrations had begun to erode and diffuse across the urban area.

\subsubsection{Changes in Residential Segregation Between Occupational Groups}

Rising new immigrant Asian, Hispanic, and Caribbean minority groups have tended to locate between the traditional core areas of non-Hispanic whites and blacks, blurring the boundaries between them and making their cores less homogeneous. Simultaneously, native and immigrant minority groups have been moving out toward the suburbs, making the suburbs more diverse as well. As a result, new spatial constellations of group locations have been emerging within the historic patterns of high levels of white-black residential segregation. Since these groups also tend to be concentrated in specific occupational niches, this has affected the residential segregation between occupational groups.

Dissimilarity indices report the level of segregation between two groups, with values above 0.6 being considered high (Massey et al. 2009, p. 77). Table 21.1 reports the indices of dissimilarity for all the occupational groups, revealing their residential concentration relative to each other at the FUA metropolitan level. Overall, the dissimilarity between occupational groups is relatively low and has changed only slightly between 2000 and 2017. The dissimilarity between the Top-Bottom occupational groups changed the most-increasing from 0.35 in 2000 to 0.38 in 2017 , approaching a moderate level of segregation. Middle-Bottom segregation remains low at 0.15 and 0.19 for 2000 and 2017, while Top-Middle remains nearly the same at 0.25 and 0.26 , respectively.

Table 21.1 Indices of dissimilarity (multiplied by 100)

2013-2017

\begin{tabular}{|lcccccccccc|cc|c|}
\hline & MAN & PRO & APR & CLE & SER & CRA & MAC & UNS & UNE & TOP & MID & BOT \\
MAN & & 16 & 54 & 30 & 27 & 47 & 42 & 44 & 39 & & & \\
PRO & 13 & & 48 & 25 & 22 & 44 & 37 & 39 & 34 & & & \\
APR & 53 & 49 & & 37 & 37 & 44 & 40 & 33 & 32 & & & \\
CLE & 28 & 25 & 35 & & 17 & 33 & 26 & 26 & 24 & & & \\
SER & 21 & 20 & 39 & 14 & & 35 & 27 & 26 & 24 & & & \\
CRA & 44 & 42 & 40 & 28 & 32 & & 33 & 29 & 37 & & & \\
MAC & 36 & 34 & 39 & 20 & 23 & 28 & & 26 & 32 & & & \\
UNS & 41 & 38 & 32 & 21 & 25 & 20 & 22 & & 26 & & & \\
UNE & 47 & 43 & 29 & 30 & 33 & 34 & 37 & 26 & & & & \\
\hline TOP & & & & & & & & & & & 26 & 38 \\
MID & & & & & & & & & & 25 & & 19 \\
BOT & & & & & & & & & & 35 & 15 & \\
\hline
\end{tabular}


Greater variation and levels of segregation emerge when we look at the dissimilarity indices between specific occupational groups. Reflecting the increasing residential concentration of Top occupations, the level of segregation between Top occupations like Managers and Professionals and both Middle and Bottom occupations like Service Workers or Unskilled Workers has generally increased. Interestingly, unemployed people have become less segregated from Top and Bottom occupations. Unsurprisingly, Managers-Professionals and Service Workers-Clerks have the lowest reported levels of segregation, likely because these are broad and overlapping white-collar occupational statuses. As already noted, the highest levels of segregation are between Top occupations and Middle or Low occupations; the dissimilarity indices between Middle and Low occupations are lower overall. Finally, ManagersAssociated Professionals are approaching what is considered to be high levels of segregation (0.53 in 2000 and 0.54 in 2017).

Location quotients describe a group's share in a given neighborhood relative to its share of the overall metropolitan population. We computed location quotients for all the occupational groups at the tract level. Figure 21.3 above maps the Top and Bottom location quotients across all the FUA's census tracts for 2000 and 2017. They show strikingly inverse patterns and provide strong evidence of increasing residential segregation between occupational groups over time. Bottom occupations disproportionately cluster in a ring around Manhattan, as well as the eastern end of

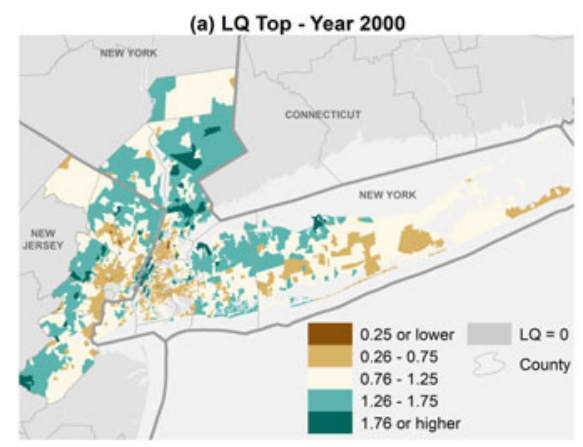

(c) LQ Bottom - Year 2000

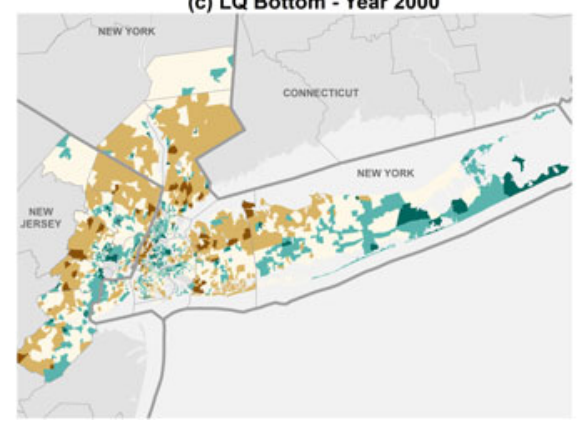

(b) LQ Top - Year 2017

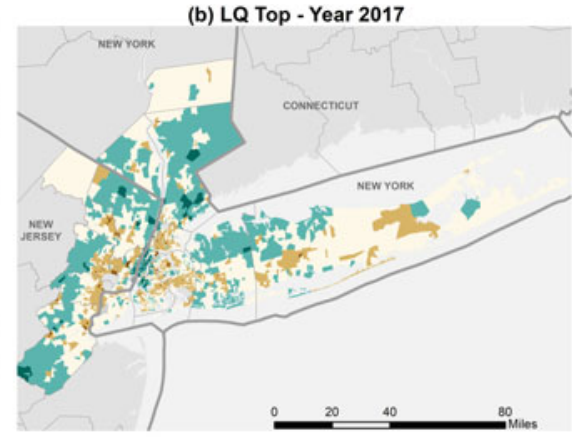

(d) LQ Bottom - Year 2017

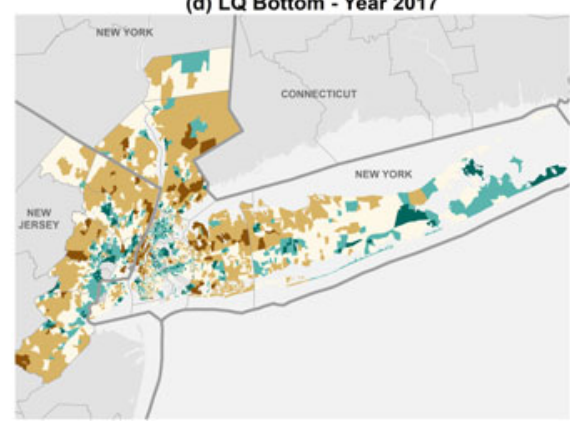

Fig. 21.3 Location quotient maps for the top and bottom occupational groups in New York 
Long Island, and around Newark and New Jersey. Between 2000 and 2017, the ring around Manhattan moves out as Bottom occupations no longer cluster in Brooklyn but grow in the areas to the north and the east of Manhattan. Conversely, Top occupational concentrations parallel those of Bottom occupations, increasingly clustering in the core of Manhattan and Brooklyn. However, what were strong concentrations of Top occupational groups in pockets stretching out from New York City along northern Long Island, in Westchester north of the City, and to suburban areas west of Newark are becoming less concentrated, presumably as other occupations move in. In short, between 2000 and 2017, Bottom occupations have generally maintained their patterns of residential concentration yet become less concentrated in the core, while Top occupations have become more concentrated in the core of Manhattan and Brooklyn and declined in their formerly suburban strongholds.

Figure 21.4 allows us to see how the Top, Middle, and Bottom occupational groups mix within and across neighborhoods. Unsurprisingly, the pattern resembles that of Fig. 21.3: High Socioeconomic Status (SES) neighborhoods cluster in an "outer ring" around the central city while Middle and Low SES neighborhoods form a barrier between that outer ring and the increasing cluster of High SES neighborhoods in the heart of the metropolitan area, New York City. Mixed SES census tracts nearly doubled in number between 2000 and 2017 and are most common on the periphery of the outer ring or in the central city where High SES neighborhoods are replacing

(a) Year 2000
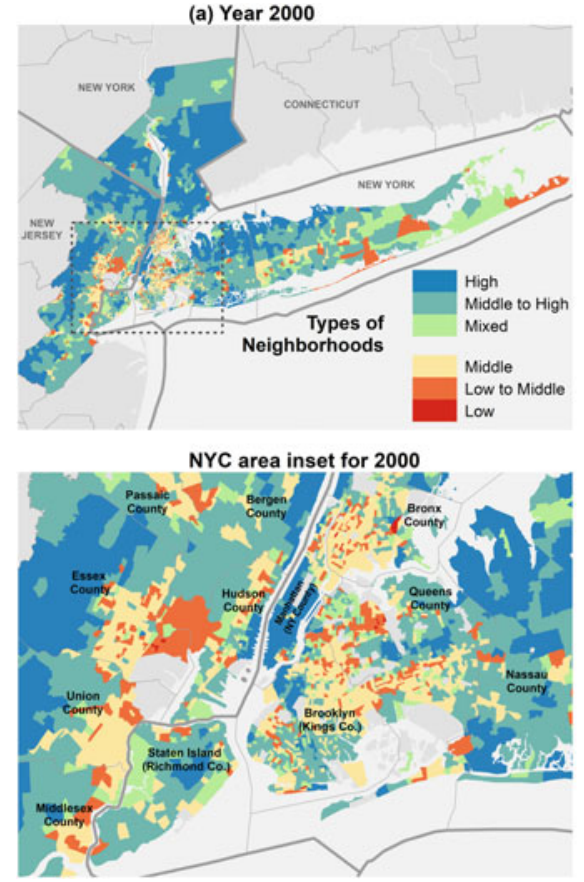

(b) Year 2017

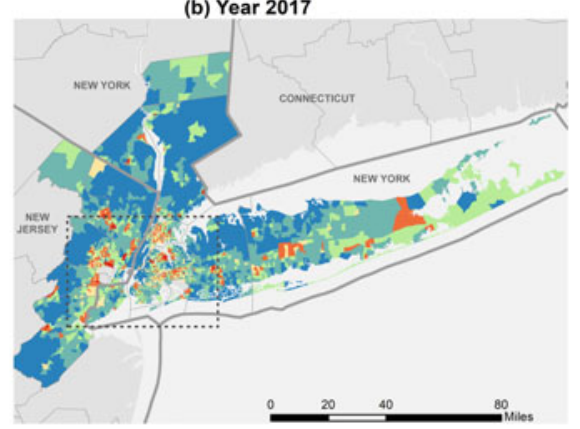

NYC area inset for 2017

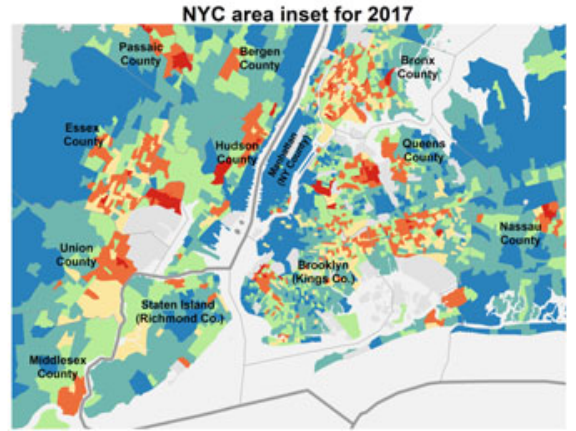

Fig. 21.4 Classification of neighborhoods by socioeconomic composition in New York 
(a) Year 2000
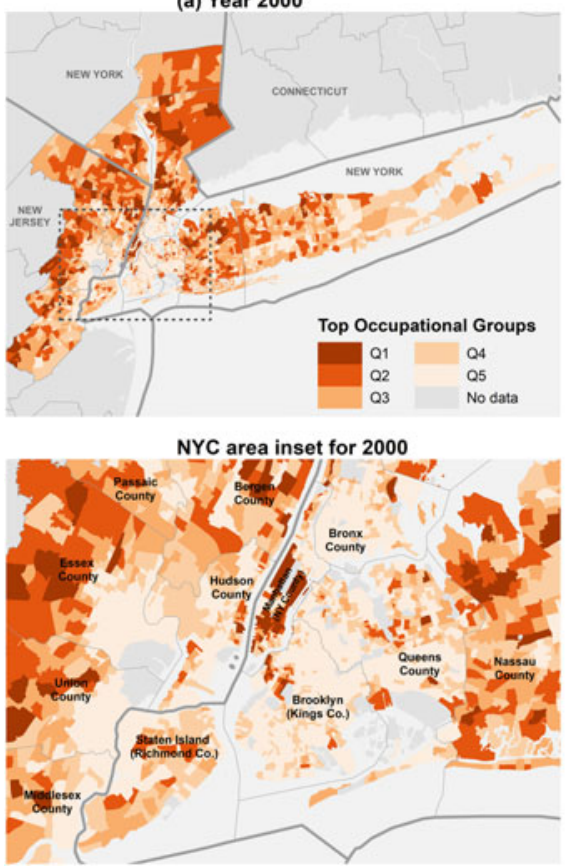

(b) Year 2017

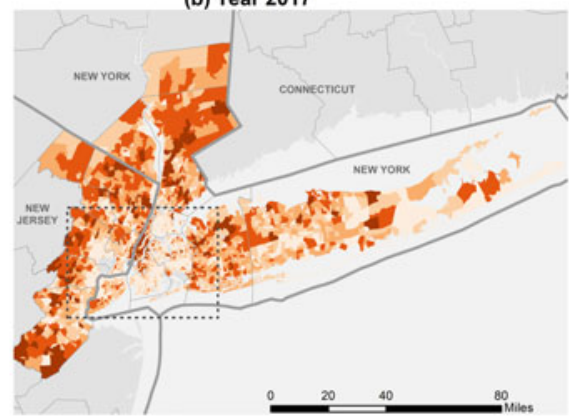

NYC area inset for 2017

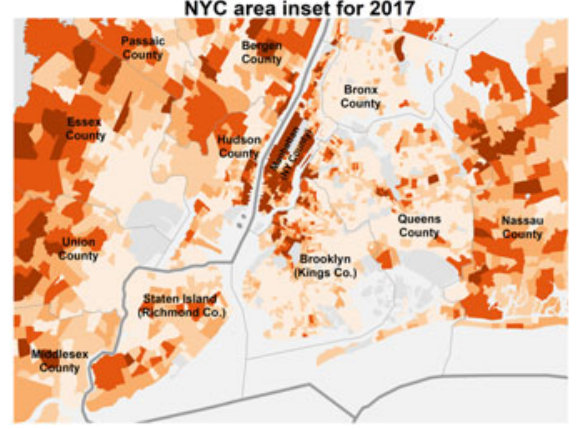

Fig. 21.5 Location of the top occupational group in New York

Low ones (i.e., parts of Brooklyn, Queens, the Bronx, and areas around Newark, NJ). This is most evident in Westchester County in New York, around Newark and New Brunswick in New Jersey, and in areas of Brooklyn and Queens with good access to the city center. A large share of neighborhoods across the metro area with High SES concentrations became more uniformly High and less Middle-High or Middle.

Figure 21.5 provides a final way to examine socioeconomic segregation by mapping the quintile distribution of Top occupational groups in neighborhoods across the metropolitan area. The neighborhoods in quantile 1 represent the top fifth of incomes for all Top occupational groups. This approach reveals an increasing concentration of top-earning neighborhoods. Between 2000 and 2017, all of the losses of Top occupational groups were from neighborhoods in quintile 5; neighborhoods gaining Top occupational groups were distributed evenly across the other quantiles. Gains at the top are most apparent in quintile 1. Looking closely, Fig. 21.5 reflects the trends discussed at the outset of the chapter: Brooklyn and Queens neighborhoods near Manhattan have moved into the top 1 or 2 quintiles from the bottom 4 or 5 over the study period, offering further evidence of the re-concentration of Top occupations and income in the core. 


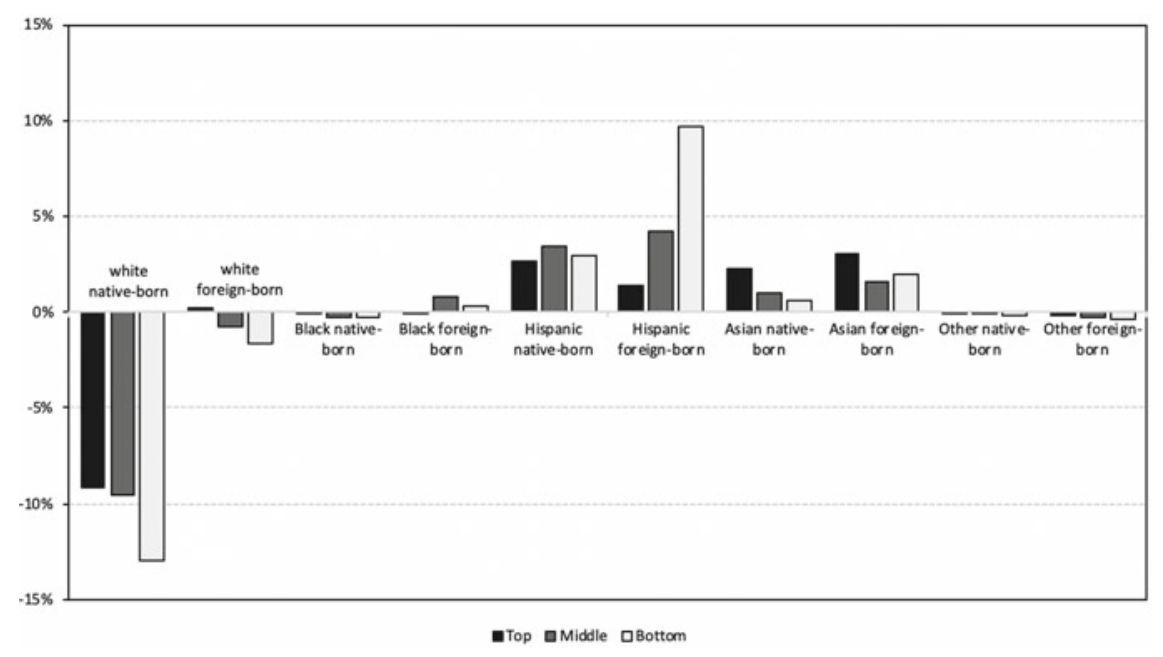

Fig. 21.6 Percentage point change in the racial and native make-up of occupational categories, New York CBSA, 2000 and 2017

\subsection{Repeated Cross-Sectional Analysis}

The following analysis uses census microdata to look at shifts in the residential location of job holders by race and occupation across the communities with at least 100,000 inhabitants (PUMAs). For each period, we cross-classified job holders by their occupational category, race, and community of residence (for example, we identified the number of black professionals living in each PUMA). This allows us to study both the changing occupational of each racial group and how the changing residential distribution of each racial-occupational group. We summarize the general patterns between 2000 and 2017 for each racial group at the community (PUMA) and aggregate New York metropolitan area (FUA) level. ${ }^{10}$ At the outset, we noted that although the adult labor force and occupational employment grew, the growth of Hispanic and non-Hispanic Asians, along with the stability of the non-Hispanic black population masked the significant decline in non-Hispanic whites in the region. Figure 21.6 clearly reflects these trends.

\subsubsection{Non-Hispanic Whites}

The total, working-age, and employed populations of non-Hispanic whites (both native-born and immigrant) all declined significantly in the FUA over the study

\footnotetext{
${ }^{10}$ Remember that PUMAs are too large to be neighborhoods-and in some cases represent one or more counties-so we refer to them as communities. A PUMA contains at least 100,000 persons. In New York City, they correspond roughly with city-established Community Districts.
} 
period. This reflects net outflows of native-born groups to other parts of the U.S., their comparatively low fertility, and their aging populations. While the overall growth in employment drew more whites into the workforce, the non-Hispanic white share still declined across all occupational groups in a way that left non-Hispanic whites slightly redistributed toward Top occupations. ${ }^{11}$ According to our analysis, the drop in the white share of Top occupations was as large as $9 \%$ points, and even larger in Bottom occupations like services and sales (13\% points) or plant and machine operators (14\% points).

Interestingly, the net loss of non-Hispanic whites in Top occupations was concentrated in the distant upper-middle-class suburbs. As discussed in the introduction, the number of whites in Top occupations actually rose in gentrifying areas close to the Manhattan central business districts. White managerial losses were particularly large (above $20 \%$ points) in the New Jersey suburbs of Elizabeth, Englewood-Fort Lee, and New Brunswick, as well as the Bayside-Little Neck area of Queens and Bensonhurst in Brooklyn. By contrast, older and more centrally located neighborhoods like Prospect Lefferts Gardens, Crown Heights, East Williamsburg-Bushwick, and Bedford Stuyvesant in Brooklyn and Central Harlem in Manhattan had substantial gains (20\% points or more) in white managers. In short, non-Hispanic whites in Top occupations decreased their share in their long-term suburban strongholds but gained in gentrifying neighborhoods close to the urban core.

\subsubsection{Non-Hispanic Blacks}

Non-Hispanic black managers and professionals presented a mirror image of the white pattern. While the occupational distribution among blacks was relatively stable, the number and share of non-Hispanic black managers and professionals decreased in the central city neighborhoods where non-Hispanic whites saw large increases, including central city black strongholds like Bedford-Stuyvesant, Central Harlem, East Harlem, East Williamsburg-Bushwick, Crown Heights, and Prospect Lefferts Gardens. On a net basis, black managers and professionals moved away from these central city areas and deeper into Long Island or New Jersey suburbs. Despite sharing an occupation, black managers and professionals earned substantially less than their white counterparts, which further limited their residential choices.

\footnotetext{
${ }^{11}$ Small occupational categories of Agriculture, Forestry, Fishery as well as Military were excluded from all cross-sectional analyses.
} 


\subsubsection{Hispanics}

In direct contrast to non-Hispanic whites, Hispanics gained numbers and shares in all ISCO occupations. They made the smallest gains in Top occupations like managers and professionals and the largest in Bottom ocupations like machine operators and elementary occupations. Since just under $60 \%$ of Hispanic workers are immigrants, this positioning in the labor market reflects both their low levels of educational attainment upon arrival as well as constraints on achieving further education in greater New York. It appears that the growth of the Hispanic working class has also supplanted the loss of non-Hispanic whites in Middle and Bottom occupations in certain communities. For example, the non-Hispanic white share of machine operators in the northern New York suburb of Ossining-Peekskill, where this occupation was relatively common, dropped from $64 \%$ to just under $39 \%$, while the Hispanic share in this occupation grew from 30 to $54 \%$. This is a continuation of a phenomenon noted by Waldinger (1996) in which immigrant groups find a place even in declining industries and occupations if whites were exiting them even faster than they declined. This was also true of other suburban areas like North Fork-Hamptons, White Plains, and West Milford-Wayne as well as satellite city areas like Bayonne-Kearny and Newark. As Top occupations and non-Hispanic whites shifted toward the central city area, minorities and Bottom occupations moved from the central city areas and into the inner suburbs - a literal turning inside out of the urban socioeconomic fabric of the New York metropolitan area.

\subsubsection{Non-Hispanic Asians}

The Asian story differs from that of the other groups. Like whites, they have become more concentrated in Top occupations (specifically managerial and professional occupations), but their immigrant origins initially clustered them in Middle and Bottom occupations. This represents great progress; the share of Asian workers who are managers rose from 14 to $19 \%$, while the Asian share of all managers rose from 9 to $15 \%$. In general, Asians are now more likely than other minority groups to hold Top and Middle occupations, with managerial, professional, technical, and clerical positions accounting for over $60 \%$ of all Asian employment in the New York FUA. Since almost $90 \%$ of Asians in the labor force are foreign born, this reflects both significant upward mobility for them as well as the higher levels of educational attainment among Asian immigrant groups compared to other immigrant groups (Kasinitz et al. 2009).

The rate of occupational change was relatively stable across communities, with larger shifts among Top occupations and smaller ones for Bottom occupations. In 2000, Asian managers and professionals were concentrated either in central Manhattan, Brownstone Brooklyn, Northeast Queens, or the ring of upper-income suburbs 30-40 miles distant from Manhattan. The single largest number of managers 
lived in and around Saddle River, New Jersey, while the Upper East Side in Manhattan had the highest share of managers. Because employment in the managerial and professional occupations grew substantially over the period, their numbers increased in almost every community, with only the Upper East and Upper West Sides and Kingsbridge losing numbers and share. Some large gains in the numbers of managers and professionals occurred as expected in well-established uppermiddle-class communities, but they also took place in the neighborhoods closely ringing Manhattan, such as Jersey City (sometimes called New York City's sixth borough), and Brooklyn Heights, Fort Greene, Bedford-Stuyvesant, Williamsburg, and Greenpoint, just across the East River from Manhattan.

A few communities that gained managers and professionals also attracted those with craft and trade occupations (Englewood-Fort Lee and Bayside-Little Neck). This out-migration of managers and professionals is consistent with the general movement of minority groups that have achieved higher socioeconomic levels out of central city areas, while Bottom occupations like craft and trade production saw a reshuffling within the city core, with neighboring areas often seeing some of the greatest gains and losses. As Asian managers and professionals moved out and away from the central city and toward more suburban and wealthier areas, Bottom occupations reshuffled within the urban core.

\subsection{Conclusion}

For many years, European scholars worried that the cities of Western Europe might be moving toward an American model, with the middle class moving to suburban jurisdictions in a way that would undermine the high levels of social provision in the big cities. The continued commitment of the professional and managerial occupations to dense central city locations often sustained these high levels of social provision (Häussermann 2005; LeGales 2002; Tammaru et al. 2015). Ironically, as European metropolitan areas get less dense and more spread out, the New York metropolitan area may be moving in a more (traditional) European direction, where Top occupations are becoming more concentrated in and around the center and the post-industrial working classes are being repositioned in the inner suburbs (Ehrenhalt 2013).

At the same time, the New York region has undergone a racial, ethnic, nativity, and gender transition that is just beginning to be widely felt in West European cities. Not only do native-born, non-Hispanic whites make up a fairly small minority of the central city population (with less than a fifth of the city's residents living in households headed by native-born, non-Hispanic whites), but this group accounts for only $35 \%$ of the total FUA population. While they remain the single largest race and nativity group, they are a diminishing plurality. No other single group has risen to supplant them. The region's next largest groups live in foreign-born Hispanic households (16.2\%), foreign-born non-Hispanic Asian households (10.9\%), native-born black households 
(10.1\%), native-born Hispanic households (9.5\%), and foreign-born non-Hispanic white households $(8.3 \%)$.

Given that the occupational structure of the regional labor market is slowly tilting toward managerial and professional occupations that require higher levels of education, that white males hold a diminishing share of those occupations, and that younger cohorts of white males are too small to replace aging white males, new patterns of opportunity and constraint are opening up in the regional labor market. The educational attainment of many minority and immigrant groups is rising across generations. Whether and how the growing racial-ethnic-gender-nativity groups get access to opportunities for career advancement will be the key to whether the region becomes less or more equitable. Many informal and formal factors shape which groups can access what employment opportunities. As recent work by Chetty and colleagues (2018) shows, New York City and its surrounding region have done a slightly better job in promoting upward mobility from the lowest income quintile than might be expected, given their finding that high levels of segregation and poverty generally hinder upward mobility. This may reflect how institutions of higher education, particularly the City University of New York, can play a critical role in opening pathways of career advancement. In our view, however, the public and private elites of the city as well as the region have not put nearly enough effort into making sure these pathways are open to disadvantaged groups. We hope that the increase of elites living among less advantaged groups in central neighborhoods will provide a social basis for new thinking in this regard, even as it raises inequality within them.

\section{References}

Alba RD (2009) Blurring the color line: the new chance for a more integrated America. Harvard University Press, Cambridge, MA

Chetty R, Friedman J, Hendren N, Jones M, Porter S (2018) The opportunity atlas: mapping the childhood roots of social mobility. NBER working paper series, 25147

Ehrenhalt A (2013) The great inversion and the future of the American City. Vintage Books, New York City, NY

Frey W (2018) Black-white segregation edges down since 2000, Census data show. https://www. brookings.edu/blog/the-avenue/2018/12/17/black-white-segregation-edges-downward-since2000-census-shows/. Accessed 30 Sept 2019

Gaumer E (2018) Selected initial findings of the 2017 New York City housing and vacancy survey, vol 2017. New York City, NY. https://www1.nyc.gov/assets/hpd/downloads/pdfs/about/2017hvs-initial-findings.pdf

Häussermann H (2005) The end of the European City? Eur Rev 13(2):237-249

Hoque AA, Clarke JA (2015) On variance estimation for a gini coefficient estimator obtained from complex survey data. Commun Stat Case Stud Data Anal and Appl 1(1), 39-58. https://doi.org/ $10.1080 / 23737484.2015 .1044050$

Kasinitz P, Mollenkopf JH, Waters MC, Holdaway J (2009) Inheriting the city: the children of immigrants come of age. Russell Sage Foundation, New York, NY

LeGales P (2002) European cities. Oxford University Press, Oxford

Ley D (1996) The new middle class and the remaking of the central city. Oxford University Press, New York 
Logan JR, Stults BJ (2011) The persistence of segregation in the metropolis: new findings from the 2010 census. Providence, RI. https://s4.ad.brown.edu/Projects/Diversity/Data/Report/report2.pdf

Logan JR, Xu Z, Stults B (2014) Interpolating U.S. decennial census tract data from as early as 1970 to 2010: a longitudinal tract database. Prof Geogr J Assoc Am Geogr 66(3):412

Lynch JA (2014) Cross-national perspective on the American welfare State. In: Béland D, Morgan KJ, and Howard C (eds) Oxford Handbook of U.S. Social Policy. Oxford University Press, New York City, NY. https://doi.org/10.1093/oxfordhb/9780199838509.013.023

Massey DS, Rothwell J, Domina T (2009) The changing bases of segregation in the United States. Ann Am Acad Polit Soc Sci 626(1):74-90

New York City Rent Guidelines Board (2018) 2018 housing supply report. New York City, NY. https://rentguidelinesboard.cityofnewyork.us/wp-content/uploads/2019/08/18HSR.pdf

O*NET (2019) O*NET Resource Center. https://www.onetcenter.org/overview.html

Paybarah A (2019) 6 ways new rent laws will affect New Yorkers. New York Times. https://www. nytimes.com/2019/06/17/nyregion/newyorktoday/nyc-news-rent-laws-ny.html

Peñaloza R (2016) Gini coefficient for ordinal categorical data (Working Paper). https://www. researchgate.net/profile/Rodrigo_Penaloza3/publication/308150405_Gini_coefficient_for_ord inal_categorical_data/links/57db535508ae5292a376a612/Gini-coefficient-for-ordinal-catego rical-data.pdf

Reardon SF, Bischoff K (2011) Income inequality and income segregation. Am J Sociol 116(4):1092-1153

Reardon S, Townsend J (1999) SEG: stata module to compute multiple-group diversity and segregation indices. https://ideas.repec.org/c/boc/bocode/s375001.html

Schwartz AF (2015) Housing policy in the United States (Third). Taylor \& Francis Group, New York City, NY

Shearer C, Vey JS, Kim J (2019) Where jobs are concentrating and why it matters to cities and regions. https://www.brookings.edu/research/where-jobs-are-concentrating-why-it-mattersto-cities-and-regions/

Smith N (1996) The new urban frontier: gentrification and the revanchist city. Routledge, New York City, NY

Tammaru T, Ham M van, Marcińczak S, Musterd S (2015) Socio-economic segregation in European capital cities: east meets west. Routledge. https://doi.org/10.4324/9781315758879

The World Bank (2019) United State country profile. https://data.worldbank.org/country/united-sta tes?view=chart

U.S. Bureau of Labor Statistics (2019a) Consumer price index: all items in New York-NewarkJersey City, NY-NJ-PA, All Urban Consumers [CUURA101SA0]. https://fred.stlouisfed.org/ser ies/CUUSA101SA0. Accessed 5 Oct 2019

U.S. Bureau of Labor Statistics (2019b) Consumer price index: all items less shelter in New YorkNewark-Jersey City, NY-NJ-PA (CBSA) [CUURA101SA0L2]. https://fred.stlouisfed.org/series/ CUURA101SA0L2. Accessed 17 Jan 2019

U.S. Bureau of Labor Statistics (2019c) Standard occupational classification. https://www.bls.gov/ soc/

U.S. Census Bureau (2019) Quarterly residential vacancies and homeownership. First quarter 2019. https://www.census.gov/housing/hvs/files/currenthvspress.pdf

von Hippel P, Hunter D, Drown M (2017) Better estimates from binned income data: interpolated CDFs and mean-matching. Sociol Sci 4(26):641-655

von Hippel P, Scarpino SV, Holas I (2016) Robust estimation of inequality from binned incomes. Sociol Methodol 46(1):212-251

Waldinger RD (1996) Still the promised city? African-Americans and new immigrants in postindustrial New York. Harvard University Press, Cambridge, MA

Zhang W, Logan J (2016) Global neighborhoods: beyond the multiethnic metropolis. Demography 53(6):1933-1953 
Open Access This chapter is licensed under the terms of the Creative Commons Attribution 4.0 International License (http://creativecommons.org/licenses/by/4.0/), which permits use, sharing, adaptation, distribution and reproduction in any medium or format, as long as you give appropriate credit to the original author(s) and the source, provide a link to the Creative Commons license and indicate if changes were made.

The images or other third party material in this chapter are included in the chapter's Creative Commons license, unless indicated otherwise in a credit line to the material. If material is not included in the chapter's Creative Commons license and your intended use is not permitted by statutory regulation or exceeds the permitted use, you will need to obtain permission directly from the copyright holder.

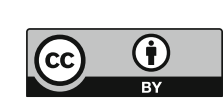

